\title{
RESEARCH
}

Open Access

\section{Factors associated with low birth weight among babies born at Hawassa University Comprehensive Specialized Hospital, Hawassa, Ethiopia}

\author{
Melese Siyoum ${ }^{*}$ (ID and Teshome Melese
}

\begin{abstract}
Background: Low birth weight is defined as infant born with weight of less than $2500 \mathrm{~g}$. It is one of the major public health problems worldwide. In Ethiopia, there are limited evidences on factors contributing to low birthweight.

Objective: To assess factors associated with low birth weight babies in Hawassa University Comprehensive Specialized Hospital, Hawassa, Ethiopia from March to April, 2018.

Methods and Materials: An unmatched case control study was conducted at Hawassa University Comprehensive Specialized Hospital. All low birth weight newborns and two unmatched controls for each case were included in the study from March to April, 2018. Data were collected through face to face interview using a structured and pretested questionnaire. The collected data were managed with Epi-data version 3.1 software and exported to the Statistical Package for Social Science (SPSS) version 22. Bivariate and multivariate binary logistic regression were used to identify factors associated with low birth weight at $p$-value $<0.05$ with their respective odds ratios and $95 \%$ confidence interval. Hosmer-Lemeshow test was used to assess goodness-of-fit.

Results: In this study 330 mother-newborn pairs (110 cases and 220 controls) were participated making 100\% response rate. Among the participants 325(98.48\%) were married, 164 (49.7\%) were Protestant, 296 (89.7\%) had ANC follow up and 212 (64.24\%) were multipara. Mothers' mid-upper arm circumference less than $220 \mathrm{~mm}[(\mathrm{AOR})=2.89$, $95 \% \mathrm{Cl}: 1.58,5.29)]$, lack of nutritional counseling $[\mathrm{AOR}=2.37,95 \% \mathrm{Cl}: 1.3,4.34]$, presence of complications during pregnancy $[A O R=2.96,95 \% \mathrm{Cl}: 1.55,5.64)]$ and lack of iron supplementations during pregnancy $[\mathrm{AOR}=2.89,95 \% \mathrm{Cl}$ : 1.58, 5.29)] were significantly associated with Low birth weight.

Conclusions: Mothers' mid-upper arm circumference less than $220 \mathrm{~mm}$, lack of nutritional counseling, presence of complications and lack of iron supplementations during current pregnancy were significantly associated with low birth weight. Counseling on nutrition during prenatal care needs attention of service providers.
\end{abstract}

Keywords: Birth weight, pregnancy, Ethiopia

\footnotetext{
* Correspondence: melesesiyoum755@gmail.com

Department of Midwifery, College of Medicine and Health Science, Hawassa

University, Hawassa, Ethiopia
}

(c) The Author(s). 2019 Open Access This article is distributed under the terms of the Creative Commons Attribution 4.0 International License (http://creativecommons.org/licenses/by/4.0/), which permits unrestricted use, distribution, and reproduction in any medium, provided you give appropriate credit to the original author(s) and the source, provide a link to the Creative Commons license, and indicate if changes were made. The Creative Commons Public Domain Dedication waiver (http://creativecommons.org/publicdomain/zero/1.0/) applies to the data made available in this article, unless otherwise stated. 


\section{Introduction}

The World Health Organization (WHO) defines low birth weight (LBW) as a birth weight of infant of 2499 gram or less regardless of gestational age [1]. Low birth weight is further classified into three categories: moderately low birth weight (1500-2499 grams), very low birth weight (VLBW), less than 1500 grams, and extremely low birth weight (ELBW), less than 1000 grams [2].

Overall, it is estimated that $15 \%$ to $20 \%$ of all births worldwide are LBW, representing more than 20 million births a year [3]. There is considerable variation in the prevalence of low birth weight across regions with estimates of LBW include $28 \%$ in south Asia, $13 \%$ in sub-Saharan Africa and 9\% in Latin America [4].

In Ethiopia, different studies showed variable prevalence of low birth weight. The variations were further reflected in the Ethiopia Demographic Household Survey with the highest rates in 2005 (14\%) and lowest in 2011 (11\%), although the trend reverts to $13.1 \%$ in 2016 report [5]. Similarly, the prevalence of LBW was $16.5 \%$ in rural Sidama zone [6], $17.9 \%$ in Southwestern Ethiopia [7], 14.6\% in Tigray region [8] and 9.1\% in Arsi zone [9]. Two studies conducted in Gondar University Hospital indicated that this prevalence ranges from $11.2 \%$ to $17.4 \%[10,11]$.

Different studies identified different factors associated with low birthweight. In Laelay Maichew districts, sex of neonate, less than four antenatal care follow ups, unwanted and unplanned pregnancy, and maternal dietary intake per 24 hours during pregnancy were associated with LBW [14]. Pregnancy induced hypertension, malaria during pregnancy, female infant and gestational age less than 37 weeks were identified as the major risk factors for low birth weight in Gondar University Hospital $[10,11]$. Low monthly income, lifestyle, and demographic area were another factors identified in south western Ethiopia [12].

Other risk factors, such as maternal age of less than 20 years, mothers with a history of abortion, lack of formal education, residing in rural areas, maternal body mass index less than $18 \mathrm{~kg} / \mathrm{m} 2$, absence of antenatal care, history of chat chewing, maternal anemia, malnutrition, poor nutrition both before and during pregnancy, extra meal during pregnancy, and lack of iron/folic acid supplementation during pregnancy were all associated with LBW $[6,8,13-18]$. Despite these varied magnitudes and factors affecting fetal birth weight, there is no published data from Hawassa University Comprehensive Specialized Hospital where more than 18 million people receive health services. Since risk factors are vary across settings, the current study was designed to identify factors associated with LBW among babies born at Hawassa University Comprehensive Specialized Hospital, southern Ethiopia.

\section{Materials and Methods}

\section{Study design and setting}

An institutionally based case-control study was conducted at Hawassa University Comprehensive Specialized Hospital (HUCSH) from March to April 25, 2018. Hawassa city is located $273 \mathrm{~km}$ south of Addis Ababa, Ethiopia. Currently, Hawassa University Comprehensive Specialized Hospital provides health services for more than 18 million people; and the average number of deliveries per month was around deliveries.

\section{Populations}

All post-partum mother-newborn pairs who visited Hawassa University Comprehensive Specialized Hospital were the source population. Live newborn babies with birth weights less than 2500grams were considered as cases and newborn babies with birth weight of 2500 grams to 4000 grams were considered as controls.

\section{Sample size determination and sampling technique}

The sample size was calculated using Open Epi Version Two statistical software for unmatched case control with the assumption of $95 \%$ confidence level, power $80 \%$, control to case ratio of one to two, minimum detectable odds ratio of two, and proportion of case among exposed group (birth interval less than two years) of $25.3 \%$ [16]. The final calculated sample size was 110 case and 220 controls. Both cases and controls were recruited on an ongoing basis until the required sample size was fulfilled.

\section{Data collection methods and tools}

Five bachelor prepared nurses were trained and collected the data through face to face interviews with the post-partal mothers. The weight of the baby was collected through observation when baby is weighted using calibrated Seca scale and rounded to 100gram. Maternal mid upper arm circumference was measured using tape meter, socio demographic data, obstetric history and presence of any complication during pregnancy were collected through maternal interview. In addition, client's medical records were reviewed for possible diagnosis of complications and gestational age. The questionnaire was initially developed in English version and translated to the local language (Amharic) for better understanding by participants. Data related to nutrition (frequency of feeding and type of diet) were collected using the Food Frequency Questionnaires (FFQs). The level of house hold food insecurity was assessed using the Household Food Insecurity Access Scale (HFIAS). This scale categorized the subjects in to four groups as secure, mild, moderate and severe insecurity [19]. 


\section{Data processing and analysis}

The collected data were checked for completeness, coded, and entered into Epi Data Version 3.1 software and exported to SPSS Version 22 for analysis.

Table 1 Socio-demographic characters of the mother who gave birth at Hawassa University Comprehensive Specialized Hospital, Hawassa, Ethiopia 2018

\begin{tabular}{|c|c|c|c|}
\hline \multirow[t]{2}{*}{ Variables } & Cases $(n=110)$ & Controls $(n=220)$ & \multirow[t]{2}{*}{$p$-value } \\
\hline & Frequency (\%) & Frequency (\%) & \\
\hline
\end{tabular}

Age of Mothers

$\begin{array}{llll}<24 & 39(35.45 \%) & 72(32.73 \%) & 0.001^{*} \\ 25-29 & 31(28.18 \%) & 103(46.82 \%) & \\ >30 & 40(36.36 \%) & 45(20.45 \%) & \end{array}$

Residence

\begin{tabular}{|c|c|c|c|}
\hline Rural & $55(50 \%)$ & $57(25.91 \%)$ & $0.001^{*}$ \\
\hline Urban & $55(50 \%)$ & 163(74.09\%) & \\
\hline \multicolumn{4}{|l|}{ Educational level } \\
\hline No formal education & $46(41.82 \%)$ & $74(33.64 \%)$ & \multirow[t]{4}{*}{$0.001^{*}$} \\
\hline Primary school & $41(37.27 \%)$ & $53(24.09 \%)$ & \\
\hline Secondary school & 12(11\%) & $29(13.18 \%)$ & \\
\hline Above secondary school & $11(10 \%)$ & $64(29.09 \%)$ & \\
\hline \multicolumn{4}{|l|}{ Religion } \\
\hline Orthodox & $12(11 \%)$ & $37(16.82 \%)$ & \multirow[t]{5}{*}{0.243} \\
\hline Protestant & $55(50 \%)$ & $112(50.91 \%)$ & \\
\hline Muslim & $37(33.64 \%)$ & $62(28.18 \%)$ & \\
\hline Catholic & $6(5.45 \%)$ & $6(2.73 \%)$ & \\
\hline Others $^{1}$ & 0 & $3(1.36 \%)$ & \\
\hline \multicolumn{4}{|l|}{ Ethnicity } \\
\hline Sidama & $40(36.36 \%)$ & $78(35.45 \%)$ & \multirow[t]{5}{*}{0.127} \\
\hline Oromo & $42(38.18 \%)$ & 64(29.09\%) & \\
\hline Amhara & $12(11 \%)$ & 19(8.63\%) & \\
\hline Wolayta & $7(6.36 \%)$ & $25(11.36 \%)$ & \\
\hline Others $^{2}$ & $9(8.18 \%)$ & $34(15.45 \%)$ & \\
\hline \multicolumn{4}{|l|}{ Occupation } \\
\hline Government Employee & $28(25.45 \%)$ & $72(32.73 \%)$ & \multirow[t]{3}{*}{0.384} \\
\hline Housewife & $59(53.64 \%)$ & $109(49.55 \%)$ & \\
\hline Others3 & $23(20.91 \%)$ & $39(17.73 \%)$ & \\
\hline Has Refrigerator No & $87(70.09 \%)$ & $116(52.73 \%)$ & \multirow[t]{2}{*}{0.001} \\
\hline Yes & $23(20.91 \%)$ & $104(47.27 \%)$ & \\
\hline \multicolumn{4}{|l|}{ Animal breeding } \\
\hline No & $66(60 \%)$ & $164(74.55 \%)$ & \multirow[t]{2}{*}{0.007} \\
\hline Yes & $44(40 \%)$ & $56(25.45 \%)$ & \\
\hline \multicolumn{4}{|l|}{ Marital status } \\
\hline Married & 108(98.18\%) & $217(98.64 \%)$ & \multirow[t]{2}{*}{0.75} \\
\hline Others4 & $2(1.82 \%)$ & $3(1.36 \%)$ & \\
\hline
\end{tabular}

Others $^{2}$ : gurage, silte, gedeo, dawuro

Others ${ }^{3}$ : student, daily laborer,

Others ${ }^{4}$ : widowed, divorced
Continuous data were categorized, mean and standard deviations computed, cross tabulation was done, and variables with very few frequencies were merged, when possible. The socio demographic and other profiles of the cases and control were compared using chi-square test.

Association between birth weight and independent variables were identified using bivariable and multivariable logistic regression model. In the bivariable model, variables with $\mathrm{p}$-value $\leq 0.2$ were selected for multivariable logistic

Table 2 Maternal and obstetrics characteristics of the mother who gave birth at Hawassa University Comprehensive Specialized Hospital, Hawassa, Ethiopia 2018

\begin{tabular}{|c|c|c|c|}
\hline \multirow[t]{2}{*}{ Variables } & Cases $(n=110)$ & Controls $(n=220)$ & \multirow[t]{2}{*}{$p$-value } \\
\hline & Frequency (\%) & Frequency (\%) & \\
\hline \multicolumn{4}{|c|}{ Gestational age (in weeks) } \\
\hline$<37$ & $41(37.27 \%)$ & $53(24.1 \%)$ & \multirow[t]{2}{*}{$0.012^{*}$} \\
\hline$\geq 37$ & $69(62.73 \%)$ & $167(75.9 \%)$ & \\
\hline
\end{tabular}

Maternal Age at first birth

$\begin{array}{clll}<18 & 40(36.36 \%) & 35(15.91 \%) & 0.001^{*} \\ 19-24 & 51(46.36 \%) & 124(56.36 \%) & \\ 25-35 & 19(17.27 \%) & 61(27.73 \%) & \\ \text { Parity } & & & \\ \text { Primi-para } & 36(32.73 \%) & 82(37.27 \%) & 0.417 \\ \text { Parous } & 74(67.23 \%) & 138(62.73 \%) & \end{array}$

Birth interval in years ( $\mathrm{n}=72$ case and 140 controls)

$\begin{array}{llll}<2 & 39(54.17 \%) & 63(45 \%) & 0.9 \\ \geq 2 & 33(45.83 \%) & 77(55 \%) & \end{array}$

ANC during the currentpregnancy

$\begin{array}{ccc}<4 \text { visits } & 71(64.55 \%) & 77(35 \%) \\ 4 \text { or more visits } & 39(35.45 \%) & 143(65 \%) \\ \text { Dietary counseling inrecent pregnancy } & \end{array}$

$\begin{array}{lcll}\text { No } & 81(73.64 \%) & 100(45.45 \%) & 0.001^{*} \\ \text { Yes } & 29(26.36 \%) & 120(54.55 \%) & \\ \text { Use of iron tablets inrecent pregnancy } & & \\ \text { No } & 63(57.27 \%) & 51(23.18 \%) & 0.001^{*} \\ \text { Yes } & 47(42.73 \%) & 169(76.82 \%) & \end{array}$

Gestational Age (in months) at 1st ANC visit (case $=79$, controls $=217$ )

\begin{tabular}{|c|c|c|c|}
\hline $1-3$ & 18(70.89\%) & $59(27.19 \%)$ & 0.713 \\
\hline $4-6$ & $56(28.1 \%)$ & 143(66\%) & \\
\hline $7-9$ & $5(6.33 \%)$ & $15(6.91 \%)$ & \\
\hline \multicolumn{4}{|c|}{ resence of pregnancy complications } \\
\hline No & $67(60.91 \%)$ & $185(84.09 \%)$ & $0.001^{*}$ \\
\hline Yes & $43(39.09 \%)$ & $35(\% 15.91 \%)$ & \\
\hline \multicolumn{4}{|c|}{ ex of the newborn } \\
\hline Female & $46(41.82)$ & $91(41.36)$ & 0.885 \\
\hline Male & 64(58.18\%) & 129(58.64\%) & \\
\hline
\end{tabular}

*significant at $P$-value $<0.05$ 
regression model. In the multivariable logistic regression, an association was considered significant at 95\% confidence level and $p$-value $<0.05$. Hosmer-Lemeshow test was used to assess goodness-of-fit.

\section{Results}

\section{Socio-demographic characteristics}

A total of 330 women (110 cases and 220 controls) participated in this study. The minimum and maximum ages of participants were 18 and 40 years respectively with a mean and standard deviation of $26.92 \pm 4.69$ years. Among the participants $325(98.48 \%)$ were married, $118(35.76 \%)$ were Sidama in ethnicity, and 164 (49.7 \%) were Protestant. There is a significant difference among cases and controls in terms of mother's age, place of residence, level of education, as well as presence of Refrigerator and animal breeding in the house (see Table 1).

\section{Maternal obstetric and child characteristics}

The minimum age at first birth was 14 years and the maximum age was 35 years with a mean and standard deviation $( \pm \mathrm{SD})$ of $21.88 \pm 3.56$ years. Similarly, the minimum and maximum gestational age at first ANC visit was four weeks and 32 weeks respectively with a mean and standard deviation of $18 \pm 5$ weeks and 2 days. In this study, 296 (89.7\%) had ANC follow up during the current pregnancy and $212(64.24 \%)$ were multipara. The minimum and maximum birth weights of the newborns were $1000 \mathrm{gm}$ and $4000 \mathrm{gm}$ respectively with a mean and standard deviation $( \pm \mathrm{SD})$ of $2800 \pm 600 \mathrm{gm}$. The mean gestational age at birth was $37 \pm 1.8$ weeks with minimum of 30 weeks and maximum of 42 weeks (see Table 2).

\section{Nutrition related characteristics of the study participants} In this study 320 (97.3\%) of participants were considered household food secure and the remaining 10 were not.Factors associated with low birth weight (Table 3).

On binary logistic regression age of the mother, MUAC, GA, occupation, presence of complication during pregnancy, nutritional counseling, residence of the mothers, level of education, ethnicity of the mothers, age at first birth, age of the mothers, and diseases, were associated with low birth weight at the P-values of $<0.2$. On multivariate logistic regression maternal MUCA less than $220 \mathrm{~mm}$, lack of nutritional counseling, presence of complication during pregnancy and lack of iron supplementation during pregnancy were significantly associated with LBW at $\mathrm{p}$ value $\leq 0.05$ and $95 \%$ confidence level (Table 4).

\section{Discussion}

This study showed that the odds of delivering low birth weight newborns among mothers who did not get nutritional counseling during ANC were two times higher than the odds of newborns born to women who received nutritional counseling. Providing antenatal care and nutritional counseling to pregnant women is effective in increasing their dietary intake, potentiating towards a successful pregnancy and healthier pregnancy outcome [20-22]. Regular prenatal nutrition counseling increase maternal weight gain and increase birth weight of the newborns [23].

The odds of delivering low birth weight newborns among mothers whose mid upper arm circumference (MUAC) was less than $220 \mathrm{~mm}$ were four times higher compared to those whose MUAC was greater than 220 $\mathrm{mm}$. This finding aligns with a study based on the Ethiopian Demographic Health Survey analysis, which concluded that maternal nutritional status is significantly associated with low birth weight [22]. In other studies, nutritional status was measured as extra meal utilization and presence of anemia during pregnancy where both factors were found to be determinants for low birth weight $[15,17,22,24]$. Maternal nutritional status affect fetal growth and weight gain.

The odds of delivering low birth weight newborns among mothers with complications during pregnancy were two times higher than their counter parts. Previous studies conducted in Gondar, Bale zone, Adwa, and

Table 3 Nutritional characteristics of mothers who gave birth at Hawassa University Comprehensive Specialized Hospital, Hawassa, Ethiopia 2018

\begin{tabular}{|c|c|c|c|c|}
\hline Variable & & Cases (\%) & Controls (\%) & $P$-value \\
\hline \multirow[t]{2}{*}{ Dietary counseling for this pregnancy } & Yes & $29(26.36 \%)$ & $120(54.55 \%)$ & $<0.001^{*}$ \\
\hline & No & $81(73.64 \%)$ & $100(45.45 \%)$ & \\
\hline \multirow[t]{2}{*}{ Iron tablets use } & Yes & $47(42.73 \%)$ & 169(76.82\%) & $<0.001^{*}$ \\
\hline & No & $63(57.27 \%)$ & $51(23.18 \%)$ & \\
\hline \multirow[t]{2}{*}{ Mid upper arm circumference } & $\leq 220$ & $35(31.82 \%)$ & $27(12.27 \%)$ & $<0.001^{*}$ \\
\hline & $>220$ & $75(68.18 \%)$ & 193(87.73\%) & \\
\hline \multirow[t]{2}{*}{ Household food security } & Food secure & 106(96.36\%) & $214(97.27 \%)$ & 0.65 \\
\hline & Food insecure & $4(3.64 \%)$ & $6(2.73 \%)$ & \\
\hline
\end{tabular}


Table 4 Factors associated with low birth weight among mothers who gave birth Hawassa University Comprehensive Specialized Hospital, Hawassa, Ethiopia 2018

\begin{tabular}{|c|c|c|c|c|c|}
\hline Variables & Cases $(=110)$ & Controls $(n=220)$ & COR $(95 \% \mathrm{Cl})$ & AOR (95\% Cl) & $p$-value \\
\hline \multicolumn{6}{|l|}{ Age of mother } \\
\hline Less than 19 & 40 & 35 & $0.61(0.34,1.09)$ & $0.41(0.18,0.93)$ & - \\
\hline $20-24$ & 51 & 124 & $0.34(0.19,0.61)$ & $0.49(0.24,1.05$ & - \\
\hline $30-40$ & 19 & 61 & $1 r$ & $1 r$ & \\
\hline \multicolumn{6}{|l|}{ Gestational Age (in weeks) } \\
\hline$<37$ & 41 & 53 & $1.87(1.14,3.07)$ & $1.79(0.98,3.28)$ & - \\
\hline$\geq 37$ & 69 & 167 & $1 \mathrm{r}$ & $1 r$ & - \\
\hline \multicolumn{6}{|l|}{ Residence } \\
\hline Rural & 55 & 57 & $2.86(1.77,4.62)$ & $1.3(0.66,2.6)$ & - \\
\hline Urban & 55 & 163 & $1 \mathrm{r}$ & r & \\
\hline \multicolumn{6}{|l|}{ Level of Education } \\
\hline Not Educated & 46 & 74 & $3.62(1.73,7.56)$ & $0.94(0.34,2.62)$ & - \\
\hline Primary & 41 & 53 & $4.5(2.1,9.6)$ & $1.72(0.68,4.37)$ & - \\
\hline Secondary school & 12 & 29 & $2.4(0.95,6.1)$ & $1.4(0.4,4.6)$ & \\
\hline Above secondary School & 11 & 64 & $1 \mathrm{r}$ & $1 \mathrm{r}$ & \\
\hline \multicolumn{6}{|c|}{ Presence of pregnancy complications } \\
\hline No & 67 & 185 & $1 r$ & $1 r$ & \\
\hline Yes & 43 & 35 & $3.39(2.0,5.74)$ & $2.96(1.55,5.64)^{*}$ & 0.001 \\
\hline \multicolumn{6}{|l|}{ Presence of Refrigerator } \\
\hline No & 87 & 116 & $3.39(2.0,5.76)$ & $1.75(.87,3.5)$ & \\
\hline Yes & 23 & 104 & $1 \mathrm{r}$ & $1 \mathrm{r}$ & \\
\hline \multicolumn{6}{|l|}{ Presence of Animal breeding } \\
\hline No & 66 & 164 & $0.5(0.32,0.83)$ & $0.7(0.35,1.43)$ & \\
\hline Yes & 44 & 56 & $1 \mathrm{r}$ & $1 \mathrm{r}$ & \\
\hline \multicolumn{6}{|c|}{ Dietary counseling during pregnancy } \\
\hline No & 81 & 100 & $3.35(2.0,5.5)$ & $2.37(1.3,4.34)^{*}$ & 0.005 \\
\hline Yes & 29 & 120 & $1 \mathrm{r}$ & $1 \mathrm{r}$ & \\
\hline \multicolumn{6}{|c|}{ Use of iron tablets during pregnancy } \\
\hline No & 63 & 51 & $4.4(2.72,7.26)$ & $2.89(1.58,5.29)^{*}$ & 0.001 \\
\hline Yes & 47 & 169 & $1 \mathrm{r}$ & $1 \mathrm{r}$ & \\
\hline \multicolumn{6}{|c|}{ Mid upper arm circumference (mm) } \\
\hline$<220$ & 35 & 27 & $3.34(1.89,5.89)$ & $2.9(1.47,5.81)^{*}$ & 0.002 \\
\hline$\geq 220$ & 75 & 193 & $1 r$ & $1 r$ & \\
\hline
\end{tabular}

southern Iran also identified the presence of HIV infection, eclampsia/preeclampsia, and anemia as significantly associated with low birth weight as these predispose the fetus to intrauterine growth restrictions $[11,16,18,24]$. It is known that any disorders that affect fetal nutritional gain during intra uterine life directly affect birth weight.

This study showed that the odds of delivering low birth weight newborns among mothers who did not use iron tablets during current pregnancy were two times higher compared to those who used iron tablets during pregnancy. Similar evidence reported in studies conducted in
Addis Ababa and Adwa, where iron utilization during pregnancy was found to be protective for LBW $[18,21]$. It was also supported by double blind randomized community trial study undergone in Nepal which show that iron supplementation during pregnancy increased birth weight by 37 gram on average [25]. Another randomized controlled trial study conducted in low income pregnant women in Cleveland counties showed that iron supplementation during pregnancy increase birth weight by 206 grams on average [26]. Despite its various contribution to health improvement, this study is not without limitations. 
One of the limitation is that since the study is conducted at a single hospital, the finding is may not be generalizable to the entire birth in the area.

Almost all factors associated with low birth weight in this study were preventable and can be controlled easily. Strengthening the integration of nutrition counseling in to ANC help could to improve maternal nutritional status during pregnancy [27]. Even though around 90\% of participants have ANC follow up, only $43 \%$ of the cases used iron. During ANC visit giving emphasis on counselling on the importance of iron use can improve the number of users and improve birth weight.

\section{Conclusions}

Lack of nutritional counseling during pregnancy, , maternal mid upper arm circumference less than $220 \mathrm{~mm}$, and presence of complication during pregnancy were significantly associated with low birth weight. Focusing on nutritional counseling and adherence to iron supplementations need great attention from care providers during prenatal care.

\section{Abbreviations}

ANC: Antenatal care; EDHS: Ethiopian Demographic and health survey; FFQ: Food frequency questionnaire; HFIAS: Household food insecurity access scale; LBW: Low birthweight; MUAC: Mid-upper arm circumstance;

SPSS: Software package for social sciences; UNICEF: United Nations Children's Fund; WHO: World Health Organization

\section{Acknowledgements}

We would like to sincerely acknowledge the mothers for consenting for the study. Our acknowledgements also go to the data collectors of the study.

\section{Funding}

This study was supported by Hawassa University, Ethiopia.

\section{Availability of data and materials}

The dataset analyzed is available from the corresponding author on reasonable request.

\section{Authors' contributions \\ MS conceived and designed the study, collected, analyzed and interpreted the data; and drafted the manuscript. TM supervised the overall process of the research. Both authors critically reviewed the manuscript and approved the final manuscript.}

\section{Ethics approval and consent to participate}

The study was approved by the IRB of College of Medicine and Health Sciences, Hawassa University. Data were collected after taking informed consent from the mothers.

\section{Consent for publication}

Not applicable.

\section{Competing interests}

The authors declare that they have no competing interests.

\section{Publisher's Note}

Springer Nature remains neutral with regard to jurisdictional claims in published maps and institutional affiliations.
Received: 27 November 2018 Accepted: 29 March 2019

Published online: 11 April 2019

\section{References}

1. Wardlaw T, Blanc A, Zupan J, Ahman E. United Nations Children's Fund and World Health Organization. Low Birthweight: Country, Regional and Global Estimates. 2005.

2. Wardlaw TM. Low birthweight: country, regional and global estimates: Unicef; 2004.

3. Kramer MS. Intrauterine growth and gestational duration determinants. Pediatr. 1987:80(4):502-11.

4. McGuire S. World Health Organization. Comprehensive implementation plan on maternal, infant, and young child nutrition. Geneva, Switzerland, 2014. Adv Nutr. 2015;6(1):134-5.

5. Central Statistical Agency[Ethiopia] and ICF International. Ethiopia Demographic and Health Survey 2011,Addis Ababa, Ethiopia and Calverton. Maryland, USA: Central Statistical Agency and ICF International; 2016.

6. Gebremedhin S, Enquselassie F, Umeta M. Independent and joint effects of prenatal Zinc and Vitamin A Deficiencies on birthweight in rural Sidama, Southern Ethiopia: prospective cohort study. PLoS One. 2012;7(12):e50213.

7. Wado YD, Afework MF, Hindin MJ. Effects of maternal pregnancy intention, depressive symptoms and social support on risk of low birth weight: a prospective study from southwestern Ethiopia. PLoS One. 2014;9(5):e96304.

8. Gebremedhin M, Ambaw F, Admassu E, Berhane H. Maternal associated factors of low birth weight: a hospital based cross-sectional mixed study in Tigray, Northern Ethiopia. BMC pregnancy and childbirth. 2015;15:222.

9. Tadesse AZ, Umeta M, Baye K. Dietary diversity during pregnancy is associated with reduced risk of maternal anemia, preterm delivery, and low birth weight in a prospective cohort study in rural Ethiopia. Am J Clin Nutr. 2016

10. Adane AA, Ayele TA, Ararsa LG, Bitew BD, Zeleke BM. Adverse birth outcomes among deliveries at Gondar University Hospital, Northwest Ethiopia. BMC pregnancy and childbirth. 2014;14:90.

11. Zenebe K, Awoke T, Birhan N. Low Birth Weight \& Associated Factors Among Newborns in Gondar Town, North West Ethiopia: Institutional Based CrossSectional Study. Indo Global Journal of Pharmaceutical Sciences. 2014; 4:74-80.

12. Tema T. Prevalence and determinants of low birth weight in Jimma Zone, Southwest Ethiopia. East Afr Med J. 2006;83(7):366.

13. Teklehaimanot N, Hailu T, Assefa H. Prevalence and Factors Associated with Low Birth Weight in Axum and Laelay Maichew Districts, North Ethiopia: A Comparative Cross Sectional Study. International Journal of Nutrition and Food Sciences. 2014;3:560-6.

14. Mumbare S, Maindarkar G, Darade R, Yenge S, Tolani MK, Patolie K. Maternal Risk Factors Associated with Term Low Birth Weight Neonates: A MatchedPair Case Control Study. Res Pap. 2011:49:25-8.

15. Mulatu H, Zepre K, Betre M, Hailemicael G. Magnitude and Factors Associated With Low Birth Weight among New Born In Selected Public Hospitals of Addis Ababa, Ethiopia, 2016 Global. Journal of Medical Research. 2017.

16. Demelash H, Motbainor A, Nigatu D, Gashaw K, Melese A. Risk factors for low birth weight in Bale zone hospitals, South-East Ethiopia : a case-control study. BMC pregnancy and childbirth. 2015;15:264.

17. Dahlui M, Azahar N, Oche OM, Aziz NA. Risk factors for low birth weight in Nigeria: evidence from the 2013 Nigeria Demographic and Health Survey. Glob Health Action. 2016;9:28822.

18. Haftu A, Gebregzabiherher Y, Weldemariam S, Gebrehiwet $H$. The Prevalence and Risk Factors for Low Birth Weight among Term Newborns in Adwa General Hospital. Northern Ethiopia: Hindawi Obstetrice and Gynecology International; 2017.

19. Coates J, Swindale A, Blinisky P. House Hold Food insecurity access scale (HFIAS) for measurement of food access:Indicator guide. New York: FANTA; 2007.

20. Inistitute of Health Economics. Determinants and prevention of low birth weight. Alberta Canada: A synopsis of the evidence; 2008. p. 1-271.

21. Mulatu H, Zepre K, Hailemicael MBG. Magnitude and Factors Associated with Low Birth Weight among New Born in Selected Public Hospitals of Addis Ababa, Ethiopia. Global Journal of Medical Research: KInterdisciplinary. 2016;17. 
22. Betew W, Muluneh EK. Determinants of Low Birth Weight among Children Aged 0 to 59 Months in Ethiopia. International Journal of Pure and Applied Sciences and Technology. 2014;25(1):14.

23. Acter SM, roy SK, Sultana M, Khatun W, Rahman R e. Effects of third trimester counseling on pregnancy weight gain, birth weight and breastfeeding among urban poor women in Bangladish. Food nutrition Bull. 2012;33(3):194-201.

24. Shahnaz R, Marzieh M, Mehrnaz M, Ch B. Survey of the Relationship Between Mother's Chronic Diseases and Low Birth Weight in Infants, Ahvaz, South of Iran. Jundishapur J Chronic Dis Care. 2014;6(2):e38259.

25. Christian P, Khatry SK, Katz J, Pradhan EK, LeClerg SC, Shrestha SR, et al. Effects of alternative maternal micronutrient supplements on low birth weight in rural Nepal: double blind randomised community trial. Bmj. 2003; 326(7389):571.

26. Cogswell ME, Parvanta I, Ickes L, Yip R, Brittenham GM. Iron supplementation during pregnancy, anemia, and birth weight: a randomized controlled trial. Am J Clin Nutr. 2003;78(4):773-81.

27. Gizaw B, Gebremedhin S. Factors associated with low birthweight in North Shewa zone, Central Ethiopia: casecontrol study. and. Ital J Pediatr. 2018;33.

Ready to submit your research? Choose BMC and benefit from:

- fast, convenient online submission

- thorough peer review by experienced researchers in your field

- rapid publication on acceptance

- support for research data, including large and complex data types

- gold Open Access which fosters wider collaboration and increased citations

- maximum visibility for your research: over $100 \mathrm{M}$ website views per year

At $\mathrm{BMC}$, research is always in progress.

Learn more biomedcentral.com/submissions 